\title{
Implant Success Predictors
}

\author{
Pravinkumar G Patil
}

International Journal of Prosthodontics and Restorative Dentistry (2019): 10.5005/jp-journals-10019-1222

Dental implant technology was improved in recent years, providing patients with unparalleled levels of effectiveness, convenience, and affordability. Rehabilitation of the incomplete dentition by means of osseointegrated dental implants represents a highly predictable and widespread therapy. Although dental implants are proven to be a predictable long-term treatment for patients, it is important to realize that not all implants that survive are necessarily successful. ${ }^{1}$ Successful implants are those that remain fully functional and healthy within the oral cavity. ${ }^{1}$ One of the most important predictor of implant success osseointegration is the sufficient amount of bone volume and satisfactory quality of the bone at the implant recipient site. Apart from bone volume and quality, several other patient-related factors influence the success of the implant therapy, namely, age, occlusal forces, smoking, genetics, systemic diseases, periodontal disease, etc. The biomaterial properties, design, roughness, wettability, surface topography, and surface treatment of the dental implants are also considered to be decisive factors for long-term success. Chiang et al. ${ }^{2}$ retrospectively studied total 1,161 implants from 513 patients. Total 23 items were considered to be the potential impact factors of implant success using the $C 5.0$ decision tree algorithm. They concluded that the bone density was the most important factor (with a variable importance of 0.55 ) that affected the surgical results. ${ }^{1}$ On the other hand, Busenlechner et al. ${ }^{3}$ studied total of 13,147 implants in 4,316 patients from year 2004 to 2012 at the Academy for Oral Implantology in Vienna. The potential impact factors they considered were implant length, diameter, jaw location, implant position, local bone quality, previous bone augmentation surgery, or patient related factors including osteoporosis, age, or diabetes mellitus, positive history of periodontal disease or smoking habit. After eight years of follow-ups, they found that the smoking increased the risk of implant failure by 3 -folds and a positive history of periodontal disease doubled the failure risk. ${ }^{3}$ However, rest all
Managing Editor and Senior Lecturer

International Journal of Prosthodontics and Restorative Dentistry, Division of Clinical Dentistry, School of Dentistry, International Medical University, Kuala Lumpur, Malaysia

Corresponding Author: Pravinkumar G Patil, Managing Editor and Senior Lecturer, International Journal of Prosthodontics and Restorative Dentistry, Division of Clinical Dentistry, School of Dentistry, International Medical University, Kuala Lumpur, Malaysia, e-mail: pravinandsmita@yahoo.co.in

How to cite this article: Patil PG. Implant Success Predictors. Int J Prosthodont Restor Dent 2019;9(1):3.

Source of support: Nil

Conflict of interest: None

factors were not significantly influential. With reference to wide range of influencing factors, it appears to be difficult to identify any single or few factors that would be responsible for a success of the implant treatment. However, the good host-bone volume and quality, and patients with no smoking habits and no history of periodontal disease are few of the most influencing predictors for the success of the dental implant treatment.

\section{References}

1. Clark D, Levin L. Dental implant management and maintenance: How to improve long-term implant success? Quintessence Int. 2016;47(5):417-423.

2. Chiang HJ, Tseng CC, Torng CC. A retrospective analysis of prognostic indicators in dental implant therapy using the C5.0 decision tree algorithm. J Dent Sci. 2013;8(3):248-255.

3. Busenlechner $D$, Fürhauser $R$, Haas $R$, et al. Long-term implant success at the Academy for Oral Implantology: 8-year follow-up and risk factor analysis. J Periodontal Implant Sci. 2014;44(3):102-108.

(0) The Author(s). 2019 Open Access This article is distributed under the terms of the Creative Commons Attribution 4.0 International License (https://creativecommons. org/licenses/by-nc/4.0/), which permits unrestricted use, distribution, and non-commercial reproduction in any medium, provided you give appropriate credit to the original author(s) and the source, provide a link to the Creative Commons license, and indicate if changes were made. The Creative Commons Public Domain Dedication waiver (http://creativecommons.org/publicdomain/zero/1.0/) applies to the data made available in this article, unless otherwise stated. 